\title{
openheart Systematic reviews: causes \\ of non-adherence to P2Y12 inhibitors in acute coronary syndromes and response to intervention
}

\author{
Nina Johnston, ${ }^{1}$ John Weinman, ${ }^{2}$ Lucy Ashworth, ${ }^{3}$ Peter Smethurst, ${ }^{4}$ \\ Jad El Khoury, ${ }^{4}$ Clare Moloney ${ }^{3}$
}

To cite: Johnston N, Weinman J, Ashworth L, et al. Systematic reviews: causes of non-adherence to P2Y12 inhibitors in acute coronary syndromes and response to intervention. Open Heart 2016;3:e000479 doi:10.1136/openhrt-2016000479

Received 21 May 2016 Revised 2 August 2016 Accepted 20 September 2016

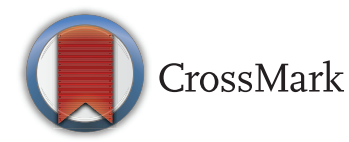

${ }^{1}$ Department of Cardiology, UCR-Uppsala Clinical Research Center and Dept. of Medical Sciences, Uppsala University, Uppsala, Sweden ${ }^{2}$ Department of Psychology, King's College, London, UK ${ }^{3}$ Atlantis Healthcare, London, UK

${ }^{4}$ AstraZeneca, Cambridge, UK

Correspondence to Dr Nina Johnston; nina. johnston@ucr.uu.se

\section{ABSTRACT}

To understand the factors associated with nonadherence to oral antiplatelet (OAP) therapy in acute coronary syndromes (ACS), and where interventions have modified these factors. Linked systematic reviews were undertaken in accordance with the Preferred Reporting Items for Systematic reviews and Metaanalysis guidelines, using CINAHL Plus, MEDLINE, PsycINFO and PubMed databases. The searches were limited to studies available in English and published from 2000 onwards; last run in June 2015. Review 1: factors. Fifteen articles were identified that reported 25 different factors associated with OAP non-adherence. Factors were categorised into: Demographic, Treatment, Healthcare System Processes, Clinical, Opportunity (ie, factors outside the patients, such as cost and healthcare access) and Psychosocial. It was not possible to determine if any of these factors were more impactful than others, either overall or temporally. Review 2: interventions. Six articles were identified that described interventions targeting adherence in patients with acute coronary syndromes (ACS)/coronary artery disease (CAD). Four broad categories of intervention were identified: treatment counselling and education, educational materials, SMS reminders and telephone monitoring and reinforcement delivered different practitioners. Only reminder-based interventions had a consistently successful impact on adherence outcomes at both 3 and 12 months. A number of factors are associated with OAP nonadherence, and encouragingly, there is some evidence of the effectiveness of intervention to modify treatment adherence in patients with ACS/CAD. Future evaluations ensuring a better cohesion between the factors studied as associated with non-adherence and those targeted by intervention would further increase understanding and lead to improved results.

\section{INTRODUCTION}

Current evidence demonstrates that adherence $^{1}$ to secondary prevention medication in acute coronary syndromes (ACS) is suboptimal across the globe ${ }^{2}$ in terms of both persistence $^{3}$ with treatment and compliance with dosing instructions throughout the recommended duration of treatment. Non-adherence to oral antiplatelet (OAP) medications is associated with worse outcomes. Recent studies in patients with coronary artery disease (CAD) suggest a benefit of extended dual antiplatelet therapy (DAPT) beyond 1 year, highlighting the importance of this issue. ${ }^{4}$

Adherence is a complex health behaviour with many determining factors, ${ }^{5}$ which can vary among individuals and change over time from uptake to longer term persistence. Interventions designed to target these factors have the potential to improve patient outcomes. An explicit examination of these different factors, how they may change over the course of treatment and what interventions have been successful has not been conducted.

Furthermore, while published interventions have been shown to significantly improve adherence in patients with ACS and those prescribed OAPs, these have varied significantly in their design. Even though this variation is good in terms of the broad evidence base for intervention efficacy, it can make it difficult to easily identify the optimal intervention for a particular causal factor and how this may vary over time.

In the light of this uncertainty, we have conducted two closely linked systematic reviews. The first review aimed to understand factors associated with non-adherence to OAPs in ACS and examine how the impact of these factors may change over time. The second review looked at adherence interventions in $\mathrm{CAD}$ populations, to determine what optimal interventions may look like over the time span of the treatment course. We then aimed to combine insights from both reviews in the hope of identifying opportunities for improving future intervention designs. 


\section{Definition of reviews}

Review 1: factors-factors associated with patient nonadherence to OAPs in ACS and how these vary over the treatment time frame.

Review 2: interventions-interventions and their behaviour change components that have demonstrated positive outcomes on the identified factors and adherence in patients with CAD.

\section{METHODS}

The systematic reviews were performed using PRISMA guidelines. ${ }^{6}$ This process is described in more detail below and figures 1 and 2 show the outcomes of this process in terms of inclusion and exclusion of papers.

\section{Search strategy}

For both reviews, we searched the following computerised databases: CINAHL Plus, MEDLINE, PsycINFO and PubMed and included studies from 2000 to June 2015. The search terms used were:

\section{Review 1: factors}

A: (acute coronary syndrome or ACS or STEMI or ST segment elevation myocardial infarction or NSTEMI or non-ST segment elevation myocardial infarction or myocardial infarction or MI or unstable angina or percutaneous coronary intervention or PCI or stent* or coronary artery disease or $\mathrm{CAD}$ or ischaemic heart disease or ischemic heart disease)

AND

B: (persist* or discontinu* or adheren* or complian* or concord* or nonadheren* or noncomplian* or nonconcord*or medication use)

AND
C: (clopidogrel or prasugrel or ticagrelor or thienopyridines or P2Y12 inhibitors or Oral antiplatelets or OAP or Dual antiplatelet therapy or DAPT)

\section{Review 2: interventions}

A and B as per 'Review 1: Factors' above plus:

C: (interven* or randomised controlled trial or RCT)

In addition, reference list reviews of identified relevant papers were also conducted, and both sets of search findings were considered for inclusion in either part of the review.

\section{Inclusion and exclusion criteria}

\section{Review 1: factors}

We included papers in which: all participants were prescribed an OAP after an acute coronary event or a separate analysis of factors correlated with OAP adherence was available; adherence or discontinuation and at least one predictor of non-adherence was measured, and the association between them was statistically examined.

We excluded papers in which: participants were prescribed aspirin only, and in which OAP discontinuation was physician-initiated.

\section{Review 2: interventions}

We included adherence interventions in which: participants were diagnosed with ACS/CAD; adherence data to ACS/CAD medication were available, either primarily or as part of subanalyses.

\section{Quality analysis}

Using the following rating tools, two researchers independently conducted a quality assessment of included papers:
Figure 1 PRISMA process flow for review 1 Factors. CAD, coronary artery disease; OAP, oral antiplatelet therapy.

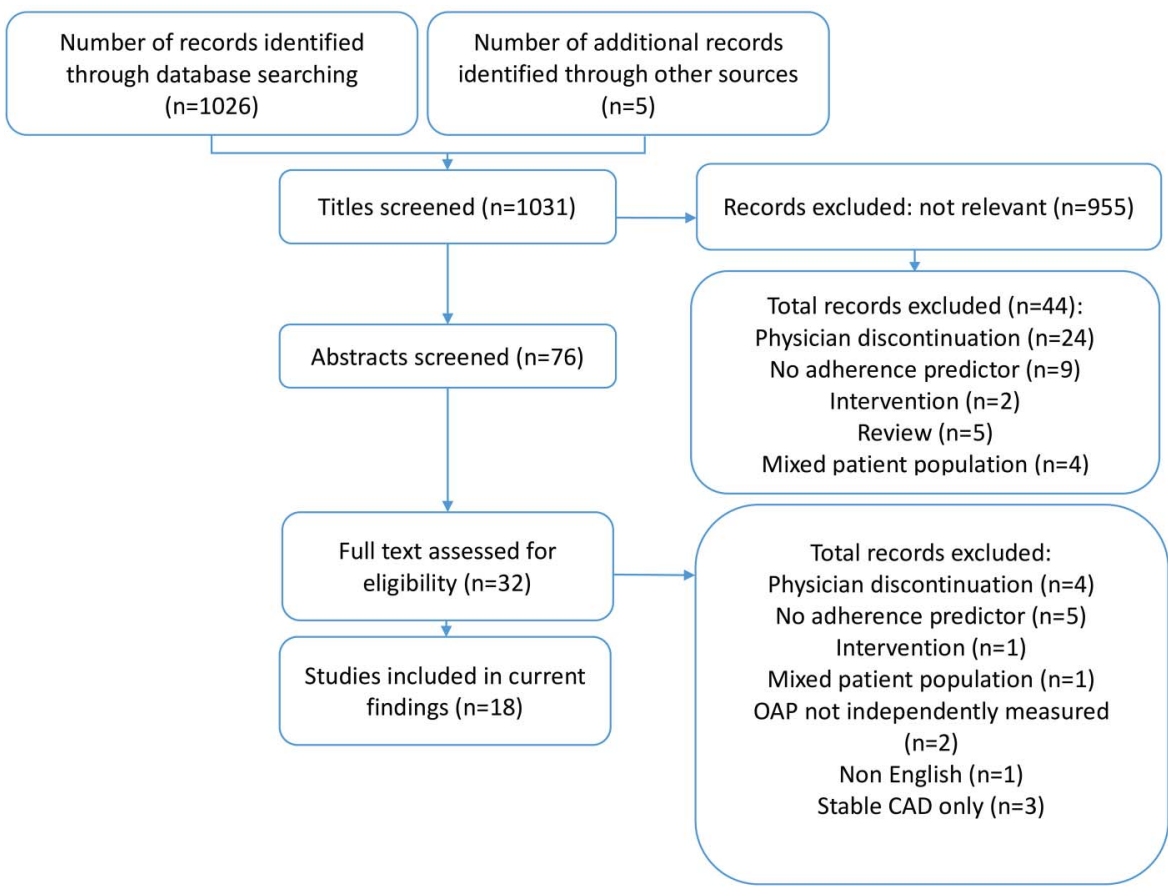


Figure 2 PRISMA process flow for review 2 Interventions. ACS/ $\mathrm{CAD}$, acute coronary syndromes/ coronary artery disease; OAP, oral antiplatelet therapy.

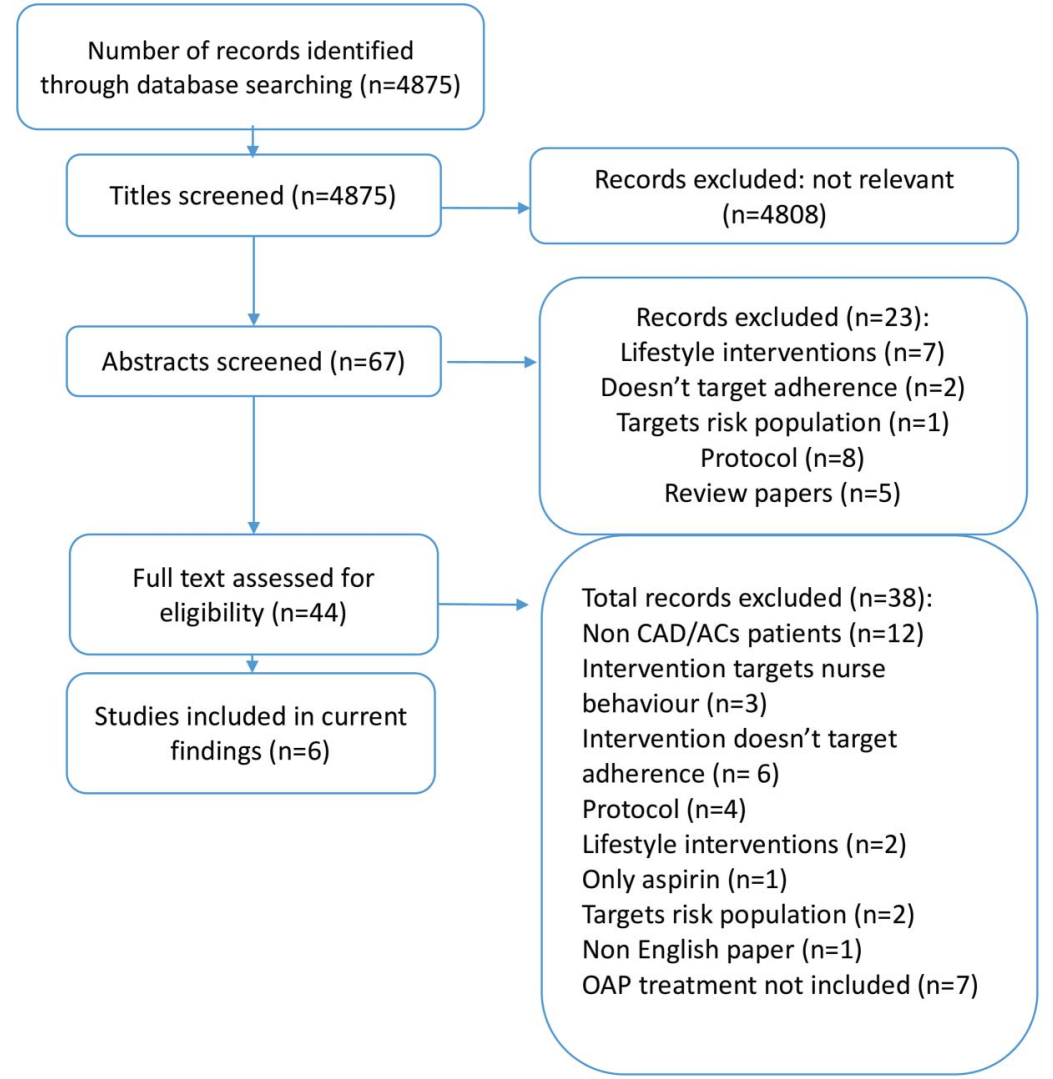

Review 1: factors

STrengthening the Reporting of OBservational studies in epidemiology-STROBE ${ }^{7}$

Studies were included if they were able to demonstrate positive outcomes on all of the relevant components of the checklist.

\section{Review 2: interventions}

\section{Jadad scale ${ }^{8}$}

Studies were included if they scored 4 points or more on the Jadad scale or if appropriate compensations had been made to mitigate quality factors out of the control of the researchers.

Discrepancies were resolved by joint review and consensus.

\section{Data extraction}

In addition to data on quality assessment, two individuals independently extracted data from all identified studies based on predefined data extraction strategy.

Data were initially extracted to explore factors impacting adherence overall. Since there were insufficient data for a separate analysis of the different categories of nonadherence, the data are presented as a combined set of findings for factors impacting adherence overall. However, the different types of adherence are included on a study-by-study basis in table 1 .

Since the cut-off definitions of 'older' and 'younger' age were not consistent across the studies, where age was cited as a predictive factor, data were further explored to determine direction and the age cut-off (where this was not explicitly listed, the mean age of the non-adherent group was used as the age cut-off criterion).

\section{Data analyses}

Meta-analysis was not appropriate for either review because of the methodological heterogeneity. Thus, a narrative review process was conducted, whereby results have been synthesised and similarities and differences explored and described descriptively. ${ }^{9}$

\section{RESULTS \\ Review 1: factors}

Overview

Fifteen studies from seven countries met the inclusion criteria. ${ }^{10-24}$ The majority of studies reviewed adherence to clopidogrel, ${ }^{1011} 1315-1724$ one to prasugrel, one to ticagrelor and the remaining to either thienopyridines or P2Y12 inhibitors. The studies included a total sample size of 21954 patients, with a mean sample size of 1464 (range 184-10 465) patients, with a mean of $75 \%$ men per study. An overview of these studies is provided in table 2.

\section{Study methods and settings}

Eleven studies were prospective observational studies; ${ }^{10-17} 192022$ four were retrospective database studies. ${ }^{18} \quad 212324$ A single study was conducted in a ary care or registry/prescription data. primary care setting, ${ }^{10}$ with the rest being from second- 
Table 1 Overview of studies exploring factors relating to adherence to OAPs, including study design, significant outcomes and measurement time points

\section{country}

Author, year,

Bally, 2012,

Switzerland

Blich, 2012, Israel

Deghani, 2014, Spain Ferreira-Gonzalez,
2010, Spain

Gencer, 2015,

Switzerland

Kubica, 2015,

Poland

Melloni, 2009, USA
Study type, collection methods, sample size

Observational self-report (questionnaire to GPs and patients)

$\mathrm{n}=204$

Observational self-report, interview with physician, medical record review $\mathrm{n}=314$

Prospective, observational registry data review $\mathrm{n}=248$

Prospective self-report (interviews with patients), secondary care $\mathrm{n}=1622$ (182 on clopidogrel) Prospective self-report (interviews with patients), secondary care $\mathrm{n}=3055$ (2597 on P2Y12 inhibitor)

Prospective, observational, prescription database review $\mathrm{n}=184$

Prospective self-report (interviews with patients), secondary care $\mathrm{n}=1077$ (816 on clopidogrel)
Significant factors impacting non-adherence

Demographic

- Older age

Treatment

- Side effects (experienced)

Demographic

- Unemployed

- Ethnicity (non-Jew)

- Low socioeconomic status

System process

- No referral to cardiologist at discharge

- No medication instruction at discharge

Demographic

- Older age

- Ethnicity (non-white)

- Female gender

Clinical

- Prior cardiovascular procedure

Treatment

- Side effects (experienced)

Demographic

- Being an immigrant

Treatment

- Concomitant drugs (psychotropic)

Demographic

- Older age

Treatment

- Side effects (experienced)

Opportunity

- Cost

Psychosocial

- Low treatment necessity

Demographic

- Male gender

Clinical

- ADP-PA during hospitalisation

- STEMI

- 3-vessel CAD*

Demographic

$x$

- Lower level of education

Clinical

- Prior cardiovascular procedure

- Comorbidities

- Less clinical follow-up

Treatment

- Greater number of medicines at discharge

Opportunity

- Cost

Psychosocial

- Forgetting

$x$

Measurement time point

(postdischarge; months) 


\begin{tabular}{|c|c|c|c|c|c|c|}
\hline $\begin{array}{l}\text { Author, year, } \\
\text { country }\end{array}$ & $\begin{array}{l}\text { Study type, collection } \\
\text { methods, sample size }\end{array}$ & $\begin{array}{l}\text { Significant factors impacting } \\
\text { non-adherence }\end{array}$ & 1 & 3 & 6 & 12 \\
\hline Muntner, 2011, USA & $\begin{array}{l}\text { Prospective self-report } \\
\text { (interview with patient), } \\
\text { secondary care } \\
n=285\end{array}$ & $\begin{array}{l}\text { Opportunity } \\
\text { Cost } \\
\text { Access/logistics } \\
\text { Psychosocial } \\
\text { - Poor relationship with doctor } \\
\text { - Low adherence at baseline }\end{array}$ & $x$ & & & \\
\hline $\begin{array}{l}\text { Nordstrom, 2013, } \\
\text { USA }\end{array}$ & $\begin{array}{l}\text { Retrospective, prescription } \\
\text { database review } \\
n=1340\end{array}$ & $\begin{array}{l}\text { Clinical } \\
\text { Prior } \mathrm{PCl}^{\star} \\
\text { Prior depression* } \\
\text { - Prior bleeds* } \\
\text { - Pre-existing cardiovascular condition } \\
\text { Psychosocial } \\
\text { Treatment } \\
\text { Treadherence at baseline } \\
\text { - Baseline statin use* } \\
\text { Baseline anticoagulant use }\end{array}$ & & & & $x$ \\
\hline Pallares, 2009, USA & $\begin{array}{l}\text { Prospective self-report } \\
\text { (interview with patient), } \\
\text { secondary care } \\
n=257\end{array}$ & $\begin{array}{l}\text { Clinical } \\
\text { Prior cardiovascular procedure } \\
\text { Treatment } \\
\text { Side effects (experienced) } \\
\text { System process } \\
\text { No information at discharge } \\
\text { Opportunity } \\
\text { Cost } \\
\text { Access/logistics } \\
\text { Psychosocial } \\
\text { - Low treatment necessity } \\
\text { - Low understanding of treatment }\end{array}$ & & $x$ & $x$ & \\
\hline $\begin{array}{l}\text { Poh, 2009, } \\
\text { Singapore }\end{array}$ & $\begin{array}{l}\text { Prospective registry database } \\
\text { review } \\
n=207\end{array}$ & $\begin{array}{l}\text { Demographic } \\
\text { Not living with caregiver } \\
\text { Clinical } \\
\text { - Lower BMI }\end{array}$ & & & & $x$ \\
\hline $\begin{array}{l}\text { Shimony, 2010, } \\
\text { Israel }\end{array}$ & $\begin{array}{l}\text { Retrospective prescriptions } \\
\text { database } \\
n=1397\end{array}$ & $\begin{array}{l}\text { Demographic } \\
\text { Low socioeconomic status }\end{array}$ & & & & $x$ \\
\hline Spertus, 2006, USA & $\begin{array}{l}\text { Prospective self-report } \\
\text { (patient interview), secondary } \\
\text { care } \\
n=500\end{array}$ & $\begin{array}{l}\text { Demographic } \\
\text { Older age } \\
\text { Lower level of education } \\
\text { Clinical } \\
\text { Prior anaemia } \\
\text { Syste-existing cardiovascular condition } \\
\text { Sysocess } \\
\text { - No information at discharge }\end{array}$ & $x$ & & & \\
\hline $\begin{array}{l}\text { Tuppin, 2010, } \\
\text { France }\end{array}$ & $\begin{array}{l}\text { Retrospective prescription } \\
\text { database } \\
n=1056\end{array}$ & $\begin{array}{l}\text { Demographic } \\
\text { Older age } \\
\text { Treatment } \\
\text { Prior use of clopidogrel }{ }^{*} \\
\text { Clinical } \\
\text { - Comorbidities } \\
\text { Stent implantation* } \\
\text { Opportunity } \\
\text { - Cost }\end{array}$ & & & $x$ & \\
\hline
\end{tabular}


Measurement time point (postdischarge; months)

\begin{tabular}{|c|c|c|c|c|c|c|}
\hline \multirow[b]{2}{*}{$\begin{array}{l}\text { Author, year, } \\
\text { country }\end{array}$} & \multirow[b]{2}{*}{$\begin{array}{l}\text { Study type, collection } \\
\text { methods, sample size }\end{array}$} & \multirow[b]{2}{*}{$\begin{array}{l}\text { Significant factors impacting } \\
\text { non-adherence }\end{array}$} & \\
\hline & & & 1 & 3 & 6 & 12 \\
\hline Zhu, 2011, USA & $\begin{array}{l}\text { Retrospective prescription } \\
\text { database } \\
n=10465\end{array}$ & $\begin{array}{l}\text { Demographic } \\
\text { Younger age } \\
\text { Clinical } \\
\text { Comorbidities } \\
\text { PCl with no stent } \\
\text { Prior hospitalisation for cardiovascular event } \\
\text { Treatment } \\
\text { Prior use of clopidogrel }\end{array}$ & & & & $x$ \\
\hline
\end{tabular}

${ }^{*}$ Associated with greater adherence.

ADP-PA, ADP-induced platelet aggregation; BMI, body mass index; CAD, coronary artery disease; GP, general practitioner; $\mathrm{PCl}$, percutaneous coronary intervention; STEMI, ST segment elevation myocardial infarction.

\section{Time frames}

Only one study ${ }^{10}$ measured adherence at two different time points (6 and 12 months), and another ${ }^{19}$ reported data at 3 and 6 months, but this was based on the treatment indication and data were not separated out between time points. Across the studies, three examined adherence outcomes at 1 month, ${ }^{12}{ }^{17} 22$ three at 3 months, ${ }^{11} 1619$ three at 6 months, ${ }^{10} 1923$ one at 9 months ${ }^{15}$ and seven at 12 months. ${ }^{10} 131418202124$

\section{Adherence measures and analysis}

Seven studies used bespoke patient questionnaires or interviews, ${ }^{10}{ }^{12-14} \quad 16 \quad 19{ }^{20}$ one used the Morisky Medication Adherence Scale (MMAS- 8 ) ${ }^{25}$ one used a pill count mechanism,${ }^{15}$ five examined registries or hospital databases, ${ }^{18}$ 21-24 and one used mixed methods, including a bespoke questionnaire and medical records data.

Eleven studies examined relationships between factors and outcomes using logistic regression analyses, ${ }^{11-13}$ $15161820-24$ two performed a correlational analysis, ${ }^{10} 19$ one performed a stratified analysis, ${ }^{14}$ and one looked at ORs. ${ }^{17}$ In terms of the type of adherence observed, eight studies examined persistence only, ${ }^{10-14} 162022$ four compliance only, ${ }^{15172123}$ and three examined both. ${ }^{18} 1924$

\section{Factors impacting adherence}

Full results are shown in table 2. This summary presents only factors that were found to be significantly correlated with non-adherence in more than a single study. All factors identified are negatively related to adherence unless otherwise stated. Overall, 25 different causal factors were identified across the studies and we have clustered these into the following six groups:

1. Demographic variables

Demographic factors that significantly correlated with non-adherence in more than one study were older age
(>67 years), ${ }^{10121422} 23$ lower level of education ${ }^{1622}$ and ethnicity. ${ }^{11} 12$

\section{Treatment variables}

The most prevalent treatment reason given for nonadherence was experience of side effects which significantly correlated with non-adherence in all studies in which it was measured. ${ }^{10121419}$ Prior use of clopidogrel was associated with non-adherence in one study ${ }^{24}$ and greater adherence in another. ${ }^{23}$

3. Healthcare system process variables

A lack of discharge information provided to patients from the hospital was an identified factor relating to non-adherence in three studies. ${ }^{11} 1922$

4. Clinical variables

Comorbidities were measured in 11 studies, and 3 studies found a significant effect. ${ }^{1623}{ }^{24}$ Pre-existing cardiovascular disease was also related to non-adherence in two studies. ${ }^{18} 22$

5. Opportunity variables (ie, factors outside the patients, such as cost and healthcare access).

Cost was significantly related to non-adherence in five studies, ${ }^{14} \quad 16 \quad 17 \quad 19 \quad 23$ either as directly described by patients or linked to insurance/copay issues. Two studies demonstrated the negative impact of logistic/access difficulties on adherence. ${ }^{17} 19$

6. Psychosocial variables

Patient-related factors that demonstrated an impact on adherence included low treatment necessity beliefs ${ }^{14} 19$ and a previous history of low adherence. ${ }^{17} 18$

Owing to the heterogeneous nature of the studies, the limited number of longitudinal, multiple time point studies and the broad dispersion across different time frames, it was not possible to determine any clear patterns of different factors as having an impact on adherence outcomes at different times, even when collapsing the factors into the cluster groupings as shown above.

Similarly, there there was a broad range of factors studied, it was not possible to statistically determine the 
Table 2 Overview of intervention studies, including factors targeted, time frames for delivery and outcomes

Author, year,

country, sample

size, and

treatment type

Gujral, 2014,

Australia

$\mathrm{n}=200$ (100 per

group)

Lipid-lowering

agents ACE-I/ARB

or $\beta$-blocker

or $\beta$-blocker

fescription Factors

(type, setting, delivery) targeted

- Community pharmacy - Treatment

counselling on

Treatment

addition to usual care

necessity

from the community

pharmacist (monthly

adherence checks

and practical

treatment discussion)

Khonsari, 2015,

Automated text

message reminders

for 8 weeks in addition

$\mathrm{n}=62$ (31 per

group)

Cardiac

o usual care (cardiac

rehabilitation and 6-

8-week follow-up with

general'

cardiologist)

Muñiz, 2010,

Spain

$\mathrm{n}=1757$ (867

intervention 890

control)

Aspirin

Clopidogrel

$\beta$-blockers

ACE-inhibitors

ARA II Statins

Palacio, 2015,

USA

$\mathrm{n}=422(213$

intervention 209

control)

Treatment

concerns

Physician-led

interviews with

supporting

educational materials

in addition to usual

discharge information

healthcare

knowledge

- Treatment

necessity

- Treatment

concerns

- Illness

coherence

Phone-based

motivational

- Treatment

interviewing (MINT) vs knowledge necessity
Intervention time point(s) by channel/technique

Channel

0-1 1-3

Channel

Face-to-face community

pharmacy adherence

check and practical

treatment discussion

Face-to-face community

pharmacy counselling

month months months months effect size

Significant outcomes

No statistically

significant outcomes on adherence as measured by prescription refill

(MPR $\geq 80 \%$ ), or self-reported MARS at 6 and 12 months

uncovered by researchers

Researcher interviews

with patients to uncover

individual treatment

Self-efficacy
Forgetting Daily SMS reminders

Prescription refill SMS

reminders

Fortnightly telephone

calls from research team

to check receipt of SMS,

check for emergency

admissions and

appointment attendance

30-to-40 min hospital

Patient and

physician interview with

professional patient and next of kin

relationship

Signed agreement

between physician and

patient on therapeutic

aims

Written educational

materials (treatment,

illness, secondary

prevention)

Inbound telephone

support

60 min quarterly

motivational

conducted by nurse with

patient

At 8 weeks

postdischarge, $65 \%$ of participants in the

high self-reported

adherence (MMAS-8=8)

compared with $13 \%$ in

the usual-care group

$(p<0.001)$

No statistically

significant outcomes on adherence as measured

by self-reported

persistence with

treatment at 6 months.

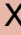

X intervention group had 


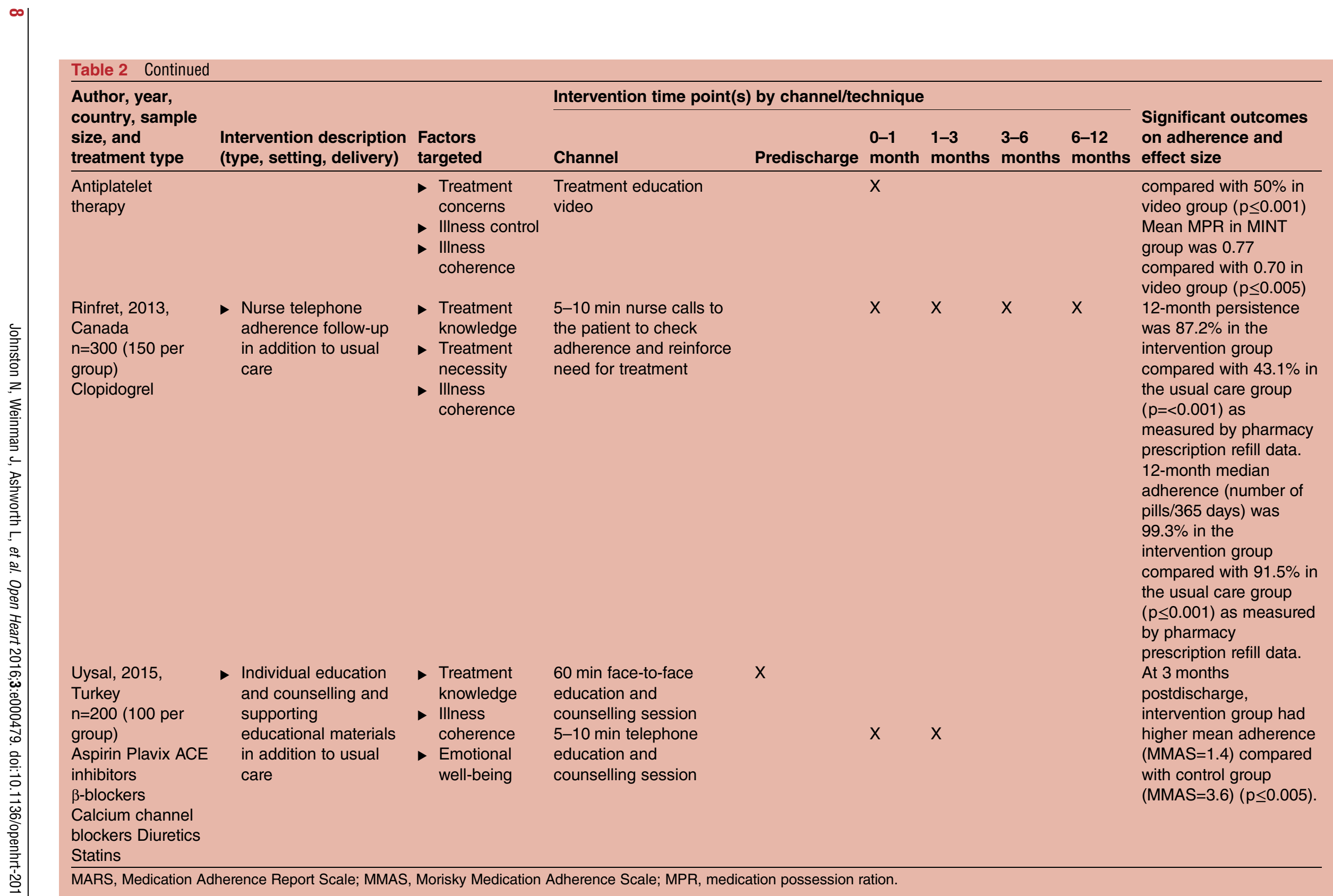


relative predictive strength of the factors, as those that were studied multiple times showed different results. Figure 3 shows the frequency of significant and nonsignificant findings for any factors that were investigated in four studies or more.

\section{Review 2: interventions}

\section{Overview}

Six studies met the inclusion criteria, ${ }^{26-31}$ four were focused on patients with $\mathrm{ACS}^{26-28} 31$ and two were focused on patients with stable CAD. ${ }^{29}{ }^{30}$ All were singlecountry studies from Australia, ${ }^{26}$ Canada, ${ }^{30}$ Malaysia, ${ }^{27}$ Spain, ${ }^{28}$ Turkey $^{31}$ and the USA. ${ }^{29}$ The studies included a total sample size of 2831 patients, with a mean sample size of 472 (range 62-1757) patients and a mean of $75 \%$ men per study. An overview of these studies is provided in table 3 .

\section{Intervention design}

\section{Intervention type and delivery}

The majority of interventions were based on treatment education and counselling, ${ }^{26} 282931$ with one being delivered by community pharmacists, ${ }^{26}$ one by physicians, ${ }^{28}$ one by nurses ${ }^{29}$ and one by the study researchers themselves. ${ }^{31}$ Only one of the education and counselling studies referred to a specific intervention methodology, namely motivational interviewing. ${ }^{29}$ Three studies included a mix of face-to-face and telephone support, with telephone support being offered after initial face-to-face counselling, either outbound ${ }^{31}$ or inbound, ${ }^{28}$ and one study including telephone calls from researchers to elicit treatment beliefs, which were then shared with community pharmacists delivering the intervention. ${ }^{26}$ When time frames were presented, initial counselling sessions lasted from 30 to $60 \mathrm{~min},{ }^{28} 2931$ with shorter follow-up sessions described as being 510 min long. ${ }^{31}$ Other interventions included treatment and prescription SMS reminders with monitoring calls from the research team, ${ }^{27}$ a signed contract between the patient and physician on treatment aims, ${ }^{28}$ and educational materials, both written and video. ${ }^{28}{ }^{29} \mathrm{~A}$ single study consisted of telephone calls from nurses who

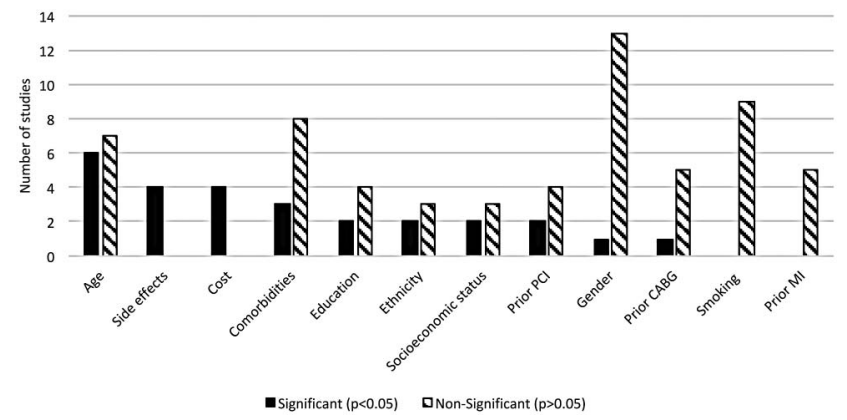

Figure 3 Relative impact of adherence-related factors that were measured in at least four studies. CABG, coronary artery bypass grafting; $\mathrm{Ml}$, myocardial infraction; $\mathrm{PCl}$, percutaneous coronary intervention. checked adherence and reinforced the importance of treatment; these calls lasted an average of $5-10$ min..$^{30}$ Only one study was multicomponent. ${ }^{28}$

\section{Behaviour change techniques}

A behaviour change technique (BCT) is defined as 'an active component of an intervention designed to change behaviour'. Technique characteristics include that it be observable, replicable and an irreducible and active component of the intervention. ${ }^{32}$ The BCT taxonomy (BCTT) was designed to provide a standardised language for describing these components. ${ }^{33}$ None of the studies explicitly referenced the taxonomy when describing their intervention design, but in order to review the interventions in a standardised way, we labelled the intervention components with their relevant BCT description as gathered from the study descriptions.

Five BCTs were common across five of the interventions: instruction on how to perform a behaviour, providing information about health consequences, salience of consequences, social support and credible source. ${ }^{26}{ }^{28-31}$ Goal setting, action planning and review activities were a feature of four interventions, ${ }^{26}{ }^{28-30}$ and three interventions provided explicit feedback on behaviour. ${ }^{26} 2829$ The motivational interviewing intervention by Palacio $e t a l^{29}$ featured a number of unique techniques compared with the other interventions. These were anticipated regret, pros and cons, comparative imagining of future outcomes, verbal persuasion of capability and social comparison. Other singularly occurring, explicit techniques were prompts/cues and monitoring of behaviours by others without feedback, ${ }^{27}$ behavioural contract $^{28}$ and reduction of negative emotions. ${ }^{31}$

\section{Time frames}

Three study interventions lasted for 12 months, with interventional calls or face-to-face counselling occurring approximately once per quarter. ${ }^{26} 2930$ Three studies included counselling or information at discharge from hospital. ${ }^{26} 2831$ The SMS intervention lasted for 8 weeks and was the only intervention that featured daily contact (via SMS) and fortnightly telephone calls to check receipt of messaging and outcomes. This intervention also included a single prescription reminder at 30 days. $^{27}$ The remaining two interventions lasted 3 months, with one including a single follow-up postdischarge intervention ${ }^{28}$ and one with two follow-ups following discharge intervention. ${ }^{31}$

\section{Adherence measures}

Four studies used self-report measures, with two using the $\mathrm{MMAS}^{25}$ with a cut-off point of eight to define adherence, and one using the Medication Adherence Rating Scale (MARS) $^{32}$ (cut-off not described or reported) and one collecting self-reported persistence data at 6 months. ${ }^{28}$ Three studies used prescription refill data to determine medication possession ratio (MPR) with $\geq 80 \%$ being considered adherent. ${ }^{26} 2930$ 
Table 3 Factors that were both identified as having an impact on adherence and addressed by intervention

\begin{tabular}{|c|c|c|}
\hline $\begin{array}{l}\text { Identified adherence factors } \\
\text { that were targeted in the intervention }\end{array}$ & Intervention used & $\begin{array}{l}\text { Modified by intervention } \\
\text { (Study) }\end{array}$ \\
\hline \multicolumn{3}{|l|}{ Treatment factors } \\
\hline \multirow[t]{3}{*}{$\begin{array}{l}\text { No information at discharge from hospital } \\
\text { (low treatment knowledge) }\end{array}$} & $\begin{array}{l}\text { Treatment and illness counselling } \\
\text { (face-to-face and telephone) }\end{array}$ & No (Gujral et al, ${ }^{26}$ 2014) \\
\hline & Written educational materials & $\begin{array}{l}\text { No (Muñiz et al, }{ }^{28} \text { 2010) } \\
\text { Yes (Uysal and Ozcan, }{ }^{31} \text { 2015) }\end{array}$ \\
\hline & Nurse-led motivational interviewing & Yes (Palacio et al, ${ }^{29}$ 2015) \\
\hline \multirow[t]{2}{*}{$\begin{array}{l}\text { Medication side effects } \\
\text { (treatment concerns) }\end{array}$} & $\begin{array}{l}\text { Treatment and illness counselling } \\
\text { (face-to-face and telephone) }\end{array}$ & No (Muñiz et al, ${ }^{28}$ 2010) \\
\hline & Nurse-led motivational interviewing & Yes (Palacio et al, ${ }^{29}$ 2015) \\
\hline \multicolumn{3}{|l|}{ Psychosocial factors } \\
\hline Patient and physician relationship & $\begin{array}{l}\text { Treatment and illness counselling } \\
\text { (face-to-face and telephone) }\end{array}$ & Yes (Uysal and Ozcan, ${ }^{31}$ 2015) \\
\hline \multirow[t]{4}{*}{ Treatment necessity } & $\begin{array}{l}\text { Treatment and illness counselling } \\
\text { (face-to-face and telephone) }\end{array}$ & Yes (Uysal and Ozcan, ${ }^{31}$ 2015) \\
\hline & $\begin{array}{l}\text { Signed agreement between physician and } \\
\text { patient }\end{array}$ & No (Muñiz, et $a l,{ }^{28} 2010$ ) \\
\hline & $\begin{array}{l}\text { Nurse-led motivational interviewing } \\
\text { (telephone) }\end{array}$ & Yes (Palacio et al, ${ }^{29}$ 2015) \\
\hline & Nurse-led telephone follow-up & Yes (Rinfret et al, ${ }^{30}$ 2013) \\
\hline \multirow[t]{2}{*}{ Forgetting } & $\begin{array}{l}\text { SMS reminders (daily treatment and } \\
\text { 30-day prescription refill) }\end{array}$ & Yes (Khonsari et $a l,{ }^{27}$ 2015) \\
\hline & Nurse-led telephone follow-up & Yes (Rinfret et al, ${ }^{30}$ 2013) \\
\hline
\end{tabular}

\section{Adherence outcomes}

Four of the six interventions demonstrated a significant impact on adherence. The 8-week SMS reminder intervention by Khonsari et $a l^{27}$ demonstrated $52 \%$ more patients self-reporting high adherence as measured by MMAS at the end of the intervention $(p=<0.001)$. The 12-month nurse-delivered motivational interviewing intervention demonstrated $14 \%$ more patients with a high MPR $(\geq 80 \%)$ at the end of the study $(\mathrm{p}=<0.001)$ and a higher mean medication intake across the 12 months $(0.77$ compared with $0.70(\mathrm{p}=<0.005)) .{ }^{29}$ The 12-month nurse adherence follow-up by Rinfret $e t a b^{30}$ demonstrated a $42.1 \%$ higher number of persistent patients in the intervention group $(p=<0.001)$ and a $7.8 \%$ higher median adherence rate $(p=<0.001)$. The 3 -month education and counselling intervention by Uysal and Ozcan, ${ }^{31}$ delivered by a research team, demonstrated higher levels of self-reported mean adherence as measured by MMAS $(\mathrm{p}=<0.005)$.

\section{Integrated findings}

This section attempts to integrate the findings from the two reviews and describes which identified OAP nonadherence factors were targeted by the interventions identified in the second review, and whether these were successful.

The interventions have attempted to target a number of determinants of treatment non-adherence using a range of approaches, and table 3 provides an overview of the findings. The determinants that have been targeted can be broadly divided into treatment and psychosocial factors, and the interventions varied in their efficacy in achieving improved adherence outcomes.

In attempting to improve information provision, the use of treatment and illness counselling ${ }^{26}$ did not result in improved adherence, whereas the use of written educational materials was successful in one study ${ }^{31}$ but not another. ${ }^{28}$ However, a 12-month nurse-led motivational interviewing intervention that targeted information provision and other factors, including treatment side effects, ${ }^{29}$ did produce significant improvements.

Three different types of psychosocial factors were targeted by a number of different interventional approaches with mixed success. The use of treatment and illness counselling over 3 months to improve the patient/physician relationship and patients' necessity beliefs was successful. ${ }^{31}$ Two of the other interventions that targeted necessity beliefs by using motivational interviewing ${ }^{29}$ and nurse telephone follow-up ${ }^{30}$ showed improved adherence outcomes, whereas the use of a signed agreement between the doctor and patient ${ }^{28}$ did not.

Finally, patient forgetting was a target for two successful interventions, one using SMS reminders ${ }^{27}$ and the other using a nurse-led telephone follow-up. ${ }^{30}$

\section{DISCUSSION}

These two linked systematic reviews sought to understand (1) the most prevalent factors impacting adherence to OAPs over the course of treatment and (2) which interventions successfully modified these factors, 
to help guide clinicians in practice to address adherence risk factors.

\section{Factors impacting adherence to OAPs in patients with ACS}

In this review, we found the number of studies addressing this issue to be limited and the evidence somewhat conflicting. In total, there were 25 different factors found to be correlated with adherence to OAPs. The factors studied seemed to be skewed to clinical and demographic variables most likely because they are easiest to capture. In general, factors that were found to be significant are well known. Patients at risk of being non-adherent included those with a higher number of comorbidities, lower education, with low treatment necessity beliefs and previous experience of side effects and those who forget. Lack of discharge information, difficulties in accessing healthcare facilities and not being followed up by a cardiologist all had a negative impact on adherence. Notably, depression, which is a frequent ACS comorbidity that is consistently linked with lower treatment adherence, was not investigated in any of the studies ${ }^{34}$ aside from Nordstrom et al who assessed prior depression only. Methodological heterogeneity in the studies made it difficult to determine if any of these factors were more impactful than others and also when during the course of the treatment they were most significant.

\section{Interventions to address non-adherence in patients with ACS/CAD}

There were four broad categories of intervention found as part of this review: treatment counselling and education (telephone and face-to-face), educational materials, SMS reminders and telephone monitoring and reinforcement delivered by a range of practitioners. Reminder-based interventions were consistent in their success, ${ }^{27}{ }^{30}$ demonstrating positive outcomes on persistence and compliance both at 3 and 12 months.

Most of the interventions incorporated educationbased BCTs, such as information provision and behavioural instruction, ${ }^{26}$ 28-31 which is an important foundation to enable behaviour change. ${ }^{35}$ Only one intervention did not feature an educational component; this was the one by Khonsari et $a l,{ }^{27}$ which used prompts/cues and monitoring (without feedback) to improve adherence behaviours. The other successful interventions provided a differing range of techniques in addition to education, with goal setting, action planning and feedback/review featuring in multiple studies, ${ }^{26}{ }^{28-30}$ which have been shown to be important in helping to turn intention into action. ${ }^{36}{ }^{37}$ Social-based techniques, such as the provision of support and providing information from a credible source, were also featured as supplementary techniques to education, although it is not possible to determine whether this was planned or simply a natural feature of who was delivering the intervention. ${ }^{26}$ 28-31 The motivational interviewing-based intervention provided the broadest range of BCTs, as it is built on core principles of communication and behaviour change. ${ }^{27}$ It is encouraging to note that a range of behaviour change techniques have been shown to improve adherence, but further work is clearly needed to confirm which are most effective for targeting the different factors causing nonadherence, which were identified in the first review.

None of the interventions reported screening for individual risk factors prior to starting the study. While the nature of the counselling-based studies, particularly the motivational interviewing intervention, lends itself to addressing individual needs, these interventions were applied to all in the same frequency, regardless of differing baseline characteristics, which may have helped determine more concretely the unmet needs of these patients. Moreover, the lack of consistent time frames or comparison between time points meant that it was not possible to draw conclusions around the most appropriate time to intervene.

\section{The impact of interventions on factors identified as impacting adherence to OAPs in patients with ACS}

The interventions in this review mainly focused on targeting psychosocial and treatment (medication)-related factors, although these were studied less frequently in the research from the first review. Factors such as illness and treatment perceptions are more modifiable and, therefore, better suited to intervention compared with factors such as age and ethnicity. ${ }^{34}$ Thus, what this review does demonstrate is an apparent disconnect between research into factors impacting adherence and the focus of adherence interventions. The body of research exploring factors impacting adherence was heavily weighted towards examining demographic and clinical variables, rather than trying to understand the more modifiable factors or to examine how demographic and clinical features are modifying outcomes.

\section{IMPLICATIONS FOR CLINICAL PRACTICE}

The present findings suggest that patients at risk for non-adherence can be identified in hospital and include those suffering from several comorbidities, those taking several medications and those with less education and fewer economic resources. Given the limited resources of most healthcare systems, the findings from this review suggest that medical adherence can be improved by early identification of the at-risk patient in need of a more intense follow-up, expansion of nurse-led programmes, particularly those that incorporate information provision, SMS reminders, goal setting, monitoring and support.

\section{LIMITATIONS AND FUTURE RESEARCH}

These findings are limited due to the heterogeneous nature of the studies in both reviews. It was not possible to determine the temporal effects of different adherence factors and intervention due to the limited 
number of longitudinal studies. None of the studies explicitly referred to BCTs, and so the intervention content provided may not be comprehensive.

Since there is declining adherence to OAPs over the course of treatment, there is a need for longitudinal studies to provide a better understanding of how delivery of interventions can best be timed. Similarly, more multiarm studies are needed to explore the impact of different intervention components at different times, particularly for those who are at higher risk of non-adherence. Finally, there is certainly scope for interventions targeting depression and its known effects on adherence.

\section{SUMIMARY}

These reviews suggest that there is a broad range of potential factors to consider in relation to adherence to OAPs, and that there is an opportunity to positively impact some of these factors, in particular those classified as treatment related and psychosocial, to improve adherence to OAPs.

The successful interventions incorporate a number of core BCTs, particularly information provision, reminders, goal setting, monitoring and feedback, and support. However, the apparent disparity between factors studied and those targeted suggests that there is opportunity for better cohesion between exploratory and interventional studies in this area. Similarly, a lack of longitudinal studies has limited our ability to understand any temporal effects that may be occurring in terms of adherence factors and the potential focus of interventions over the full treatment course.

Funding This research was funded by AstraZeneca and undertaken by Atlantis Healthcare. PS and JEK are employees of AstraZeneca. NJ has received lecture fees from AstraZeneca for education of healthcare professionals. LA and $\mathrm{CM}$ are full-time employees of Atlantis Healthcare, and JW is a part-time employee of Atlantis Healthcare.

Competing interests None declared

Provenance and peer review Not commissioned; externally peer reviewed.

Data sharing statement No additional data are available.

Open Access This is an Open Access article distributed in accordance with the Creative Commons Attribution Non Commercial (CC BY-NC 4.0) license, which permits others to distribute, remix, adapt, build upon this work noncommercially, and license their derivative works on different terms, provided the original work is properly cited and the use is non-commercial. See: http:// creativecommons.org/licenses/by-nc/4.0/

\section{REFERENCES}

1. Horne R, Weinman J, Barber N, et al. Concordance, adherence and compliance in medicine taking. London: NCCSDO, 2005;2005:40-6.

2. Desai NR, Choudhry NK, Loli AK, et al. Impediments to adherence to post myocardial infarction medications. Curr Cardiol Rep 2013;15:1-8.

3. Hughes D, Cowell W, Koncz T, et al. Methods for integrating medication compliance and persistence in pharmacoeconomic evaluations. Value Health 2007;10:498-509.

4. Zarifyan A. Continued Dual Antiplatelet Therapy Beneficial in PEGASUS-TIMI 54 and DAPT Trials. MD Conference Express. SAGE Publications, 2015.
5. Jackson C, Eliasson L, Barber N, et al. Applying COM-B to medication adherence. Eur Health Psychol 2014;16:7-17.

6. Moher D, Liberati A, Tetzlaff J, et al. Preferred reporting items for systematic reviews and meta-analyses: the PRISMA statement. Ann Intern Med 2009;151:264-9.

7. Von Elm E, Altman DG, Egger M, et al. The Strengthening the Reporting of Observational Studies in Epidemiology (STROBE) statement: guidelines for reporting observational studies. Prev Med 2007;45:247-51.

8. Jadad AR, Moore RA, Carroll D, et al. Assessing the quality of reports of randomized clinical trials: is blinding necessary? Control Clin Trials 1996;17:1-12.

9. Petticrew M, Roberts $\mathrm{H}$. Systematic reviews in the social sciences: a practical guide. John Wiley \& Sons, 2008.

10. Bally K, Buechel, Buser $\mathrm{P}$, et al Discontinuation of secondary prevention medication after myocardial infarction-the role of general practitioners and patients. Swiss Med Wkly 2013;143:w13896.

11. Blich M, Shwiri TZ, Petcherski S, et al. Clopidogrel therapy discontinuation following drug eluting stent implantation in real world practice in Israel. Cardiol Res 2012;3:67-72.

12. Dehghani P, Chopra V, Bell A, et al. Southern Saskatchewan Ticagrelor registry experience. Patient Prefer Adherence 2014;8:1427.

13. Ferreira-González I, Marsal JR, Ribera A, et al. Background, incidence, and predictors of antiplatelet therapy discontinuation during the first year after drug-eluting stent implantation. Circulation 2010;122:1017-25.

14. Gencer B, Rodondi N, Auer R, et al. Reasons for discontinuation of recommended therapies according to the patients after acute coronary syndromes. Eur J Intern Med 2015;26:56-62.

15. Kubica A, Obońska K, Kasprzak M, et al. Prediction of high risk of non-adherence to antiplatelet treatment. Kardiol Pol 2016;74:61-7

16. Melloni C, Alexander KP, Ou FS, et al. Predictors of early discontinuation of evidence-based medicine after acute coronary syndrome. Am J Cardiol 2009;104:175-81.

17. Muntner P, Mann DM, Woodward M, et al. Predictors of low clopidogrel adherence following percutaneous coronary intervention. Am J Cardiol 2011;108:822-7.

18. Nordstrom BL, Simeone JC, Zhao Z, et al. Adherence and persistence with prasugrel following acute coronary syndrome with percutaneous coronary intervention. Am J Cardiovasc Drugs 2013;13:263-71.

19. Pallares MJ, Powers ER, Zwerner PL, et al. Barriers to clopidogrel adherence following placement of drug-eluting stents. Ann Pharmacother 2009;43:259-67.

20. Poh CL, Chan MY, Lau C, et al. Prevalence and predictors of premature discontinuation of dual antiplatelet therapy after drug-eluting stent implantation: importance of social factors in Asian patients. Intern Med J 2011;41:623-9.

21. Shimony A, Zahger D, Ilia R, et al. Impact of the community's socioeconomic status on characteristics and outcomes of patients undergoing percutaneous coronary intervention. Int J Cardiol 2010;144:379-82

22. Spertus JA, Kettelkamp R, Vance C, et al. Prevalence, predictors, and outcomes of premature discontinuation of thienopyridine therapy after drug-eluting stent placement results from the PREMIER registry. Circulation 2006;113:2803-9.

23. Tuppin P, Neumann A, Danchin N, et al. Evidence-based pharmacotherapy after myocardial infarction in France: adherence-associated factors and relationship with 30-month mortality and rehospitalization. Arch Cardiovasc Dis 2010;103:363-75.

24. Zhu B, Zhao Z, Mccollam P, et al. Factors associated with clopidogrel use, adherence, and persistence in patients with acute coronary syndromes undergoing percutaneous coronary intervention. Curr Med Res Opin 2011;27:633-41.

25. Horne R, Weinman J, Hankins M. The beliefs about medicines questionnaire: the development and evaluation of a new method for assessing the cognitive representation of medication. Psychol Health 1999;14:1-24.

26. Gujral G, Winckel K, Nissen LM, et al. Impact of community pharmacist intervention discussing patients' beliefs to improve medication adherence. Int J Clin Pharm 2014;36:1048-58.

27. Khonsari S, Subramanian $\mathrm{P}$, Chinna K, et al. Effect of a reminder system using an automated short message service on medication adherence following acute coronary syndrome. Eur J Cardiovasc Nurs 2015;14:170-9.

28. Muñiz J, Gómez-Doblas JJ, Santiago-Pérez MI, et al., CAM2 Project working group. The effect of post-discharge educational intervention on patients in achieving objectives in modifiable risk factors six 
months after discharge following an episode of acute coronary syndrome, (CAM-2 Project): a randomized controlled trial. Health Qual Life Outcomes 2010;8:137.

29. Palacio AM, Uribe C, Hazel-Fernandez L, et al. Can phone-based motivational interviewing improve medication adherence to antiplatelet medications after a coronary stent among racial minorities? A randomized trial. J Gen Intern Med 2015;30:469-75.

30. Rinfret S, Rodés-Cabau J, Bagur R, et al., EASY-IMPACT Investigators. Telephone contact to improve adherence to dual antiplatelet therapy after drug-eluting stent implantation. Heart 2013;99:562-9.

31. Uysal H, Ozcan S. The effect of individual education on patients' physical activity capacity after myocardial infarction. Int $J$ Nurs Pract 2015;21:18-28.

32. Morisky DE, Green LW, Levine DM. Concurrent and predictive validity of a self-reported measure of medication adherence. Med Care 1986;24:67-74
33. Michie S, van Stralen MM, West R. The behaviour change wheel: a new method for characterising and designing behaviour change interventions. Implement Sci 2011;6:1-11.

34. Moss-Morris R, Weinman J, Petrie $\mathrm{K}$, et al. The revised illness perception questionnaire (IPQ-R). Psychol Health 2002;17:1-16.

35. Whitehead D, Russell G. How effective are health education programmes-resistance, reactance, rationality and risk? Recommendations for effective practice. Int $J$ Nurs Stud 2004;41:163-72.

36. Sniehotta FF, Scholz U, Schwarzer R. Bridging the intentionbehaviour gap: planning, self-efficacy, and action control in the adoption and maintenance of physical exercise. Psychol Health 2005;20:143-60.

37. Goodwin L, Ostuzzi G, Khan N, et al. Can we identify the active ingredients of behaviour change interventions for coronary heart disease patients? A systematic review and meta-analysis. PLOS ONE 2016;11:e0153271. 